\title{
Demógrafos sanitaristas: o remédio era a boa estatística
}

\author{
Marco Santos*
}

\begin{abstract}
Resumo
Os demógrafos sanitaristas brasileiros tiveram atuação fundamental na história da estatística do Brasil. Não só por terem trazido ao país métodos estatísticos científicos, como pela postura sempre crítica em relação às estatísticas oficiais, produzidas por burocratas sem o estofo que consideravam necessário. Do início de sua atuação como funcionários das áreas de saúde pública e higiene até a chegada de um deles à direção do principal órgão de estatística nacional - José Luiz Sayão de Bulhões Carvalho -, eles empreenderam trajetória de criação de conhecimento e de grandes polemistas em torno dos números oficiais. E o percurso dos demógrafos sanitaristas passa, necessariamente, pela sua atuação nos órgãos de saúde pública criados no Rio de Janeiro e, posteriormente, nos demais estados brasileiros.
\end{abstract}

Palavras-chave: Demógrafos sanitaristas; estatística; saúde pública e higiene.

\begin{abstract}
Brazilian demographers sanitarians had a fundamental role in the history of statistics in Brazil. Not only for bringing the country scientific statistical methods, such as the always critical stance in relation to official statistics produced by bureaucrats without the knowledge they considered necessary. From the beginning of his work as employees in the areas of public health and hygiene until the arrival of one direction of the main body of national statistics José Luiz Carvalho de Bulhões Sayão - they undertook creation path of knowledge and great polemicists around official figures. And the route of sanitarians demographers necessarily passes through its activities in the public health agencies created in Rio de Janeiro and later in other Brazilian states.
\end{abstract}

Keywords: Demographers sanitarians; statistics; public health and hygiene.

A partir do final do século 19, o panorama estatístico brasileiro da época foi amplamente dominado pelos chamados demógrafos sanitaristas, encontrados em alguns documentos com outras denominações assemelhadas como "médicos demografistas" ou "demógrafos higienistas”. Independente da alcunha que lhes pespegassem, eram todos médicos formados, quase invariavelmente com teses de doutoramento em epidemiologia ou saúde pública. Homens de ciência, devotados à solução do grave problema da insalubridade das cidades.

\footnotetext{
* Mestre em Estudos Populacionais e Pesquisas Sociais pela Escola Nacional de Ciências Estatísticas-ENCE. Funcionário do IBGE lotado no Projeto História das Estatísticas Brasileiras. correio.marco.br@gmail.com
} 
A partir de determinado momento, estes médicos tornaram-se também “demógrafos" e "estatísticos". ${ }^{1}$

Sua trajetória original, entretanto, se dá ao longo do século 19, tanto no Brasil quanto no mundo. O uso da estatística como instrumento auxiliar da saúde pública, incluindo a denominação demografia sanitária, não surgiu em terras brasileiras, embora tenha sido adotada no país pouco tempo depois de sua utilização oficial na Europa. Entretanto, o conceito de saúde pública (e de polícia médica) é bem anterior, conforme indica Leal David:

(...) a partir da expansão do mercantilismo, a necessidade de garantir a reprodução da força de trabalho e a produção crescente dá origem às práticas de "polícia médica", que visavam normatizar as ações de saúde pública nas metrópoles europeias e nas cidades recém-fundadas nas colônias. (David, 1996:99)

No Brasil, há indícios de algumas ações de polícia médica no final do século 18, mas somente a partir da vinda da Família Real ações mais próximas do moderno conceito de saúde coletiva se desenvolveram na terra brasilis, praticamente ao mesmo tempo em que se adensavam no Velho Mundo. Vale ressaltar que até fins do século 19,

esta intervenção se caracterizava pela ausência de planejamento e relativa ineficácia quanto ao controle das doenças transmissíveis, sobretudo as que grassavam nos espaços urbanos e que exigiam, para seu controle, uma intervenção mais direta sob o ambiente e sobre o parasito causador. (David, 1996:99)

De qualquer forma, gradativamente, a presença do instrumental estatístico foi evoluindo ao longo dos anos oitocentistas, abastecendo com números e oferecendo possibilidades de atuação aos órgãos de saúde coletiva (leia-se Estado). E o papel dos demógrafos sanitaristas, como homens que lidavam com este instrumental estatístico não como diletantes ou "curiosos", mas como quem conhecia o seu ofício, conhecia o método. Estes cientistas, bem antes do chamado "Movimento Sanitarista", ${ }^{2}$ já estavam debruçados na questão da saúde pública brasileira, olhando-a pelo viés das estatísticas demográficas.

\section{Origens da saúde pública no mundo}

Para entender o papel da demografia sanitária no ciclorama das estatísticas nacionais e internacionais é necessário acompanhar a evolução da saúde pública e higiene. Foi exatamente nesses ambientes onde os demógrafos sanitaristas germinaram e se desenvolveram.

Sem ter a pretensão de englobar inteiramente a vertente histórica da saúde pública no mundo, pretendo apenas localizar e dar historicidade à evolução da saúde coletiva e seus pontos de contato com a estatística. Tanto a literatura quanto os documentos pesquisados enfeixam "saúde pública e higiene" não exatamente como sinônimos mas como saberes complementares, quase indissociáveis, pelo menos no contexto em que surgiu a estatística sanitária. Podemos entender saúde pública como uma expressão designativa de um campo

1 Talvez o melhor fosse chamá-los "estaticistas", conforme definição de Nelson Senra para aqueles que produzem estatísticas. Para Senra, mesmo os estatísticos, enquanto atuando na produção de estatísticas, são "estaticistas" (Senra, 2005).

2 Movimento organizado na Primeira República, em 1918, reunindo médicos, cientistas e intelectuais que visava denunciar as trágicas condicõos sanitárias do país, especialmente nas áreas rurais, avocando uma reforma de base nos serviços federais de saúde pública. Segundo Castro Santos, foi o mais importante projeto de construção da nacionalidade brasileira. Segundo seus adeptos pregavam, as doenças grassavam menos por fatores raciais ou por características climáticas e mais pela própria natureza das endemias e que a redenção social do Brasil passava necessariamente pelo aumento do papel do Estado na Saúde Pública (Ver Lima; Hochman, 1996). 
científico de saber e de fazer referente à saúde como fenômeno social. ${ }^{3}$ Já a higiene pode ser vista como ciência que visa preservar a saúde e prevenir doenças por intermédio de práticas higienizantes. ${ }^{4}$ A estatística entraria como ferramenta que auxiliaria no levantamento prévio para ações de saúde pública e higiene e também para aferir em que medida tais intervenções obtiveram o efeito pretendido. Veremos a seguir que, consoante o surgimento e a consolidação do conhecimento teórico e empírico no âmbito da saúde pública e da prevenção sanitária, mais se aprofundava a necessidade de envolvimento de diversas disciplinas, entre as quais a estatística.

Em que momento aconteceu tal fato? Muito provavelmente, a partir do instante em que perceberam que, para atacar as endemias que flagelavam as populações, era necessário conhecer "quantos formavam a população", "quantos nasciam a cada ano", "onde viviam", "quantos morriam", "de que morriam", "onde morriam" - questões estas (entre outras) fundamentais para que a ciência médica atuasse e, consequentemente, para que o Estado atuasse.

O ferramental para que estes "quantos" e "ondes" fossem respondidos era a estatística e sua irmã siamesa, a demografia.

Naquele momento, a demografia ganhou o adjetivo "sanitária” por conta da necessidade de combate às pandemias que açoitavam a população. Mas, pelo que se constata, demografia sanitária e demografia são absolutamente a mesma disciplina: ambas estudam os mesmos temas. Suas fontes seriam as "estatísticas da vida" ou "vitais", vale dizer denominações posteriores que ela receberia.

Desta forma, é possível localizar a gênese da estatística sanitária a partir do final do século 18. Com as significativas revoluções sociais e políticas ocorridas na América e na França, o mundo estava em transformação. No dizer de Rosen, "cada vez mais os homens, tendo experimentado a transformação social súbita, achavam difícil conceber uma sociedade estática” (Rosen, 1994:113).

No roldão dessas transformações veio o Iluminismo e a Revolução Industrial. Surgiu também o germen de novas ideias e tendências para a saúde pública que iniciaria sua expansão a partir do início do século 19.

\section{Números para a saúde pública brasileira}

No Brasil, é possível localizar as primeiras tentativas consolidadas de se organizar a saúde pública a partir da chegada da Família Real ao Rio de Janeiro. Ainda não se evidenciaria um emergente projeto de medicina coletiva para o Brasil, mas algum esforço começaria a ser empreendido. Roberto Machado e colaboradores abordaram o assunto em um trabalho, procurando situar os primórdios da ação do Estado na saúde da população:

A administração portuguesa não se caracterizou, pelo menos até a segunda metade do século 18, pela organização do espaço social, visando um ataque planificado e continuado às causas de doença, agindo, por isso, de modo muito mais negativo que positivo, no que diz respeito à saúde. (Machado Apud Nunes 2000:253)

3 Ver http://www.isc.ufba.br/isc.php?externa=3. Acesso em 10/12/2013.

4 Cf. http://www.simonsen.br/its/pdf/apostilas/base-tecnica/1/higiene-e-saude-1-capitulo-1-ano-de-enfermagem.pdf Acesso em 10/12/2013. 
Para Everardo Nunes, “o estudo detalhado de documentos periódicos, cartas, ofícios e teses irá evidenciar que o tema da saúde, por si mesmo, não forma parte do projeto colonial (...)" (Nunes, 2000:253).

Esta preocupação só ocorreria no início do século 19, com a presença da Corte lusitana, quando se fará necessário o maior conhecimento da nova sede do Reino Unido português e, consequentemente, com a necessidade de melhoria da saúde de sua população. Com isso, foram criadas as primeiras escolas de Medicina no Brasil, começando por Salvador, em 1808, seguindo-se a cátedra de Anatomia no Hospital Militar e, posteriormente, pela de Medicina Operatória. Desta forma, temos a saúde pública no Brasil se desenvolvendo pari passu com a própria Medicina. Com isso, está claro que a saúde do coletivo em plagas brasileiras surgia na mesma época que no mundo, mas por caminhos um tanto diversos.

A atuação efetiva do governo na saúde coletiva iniciou-se, por estruturas administrativas determinadas pelo Príncipe Regente D. João, ao criar a Junta de Saúde Pública, em 1814. Esta recebeu a incumbência de elaborar mapas mensais de mortalidade para a capital do Brasil. Desafortunadamente, problemas operacionais impediram a concretização desta determinação real (Pereira, 1982). Em 1820, houve nova tentativa da Coroa na atuação nesta área, por intermédio da criação da Inspetoria de Saúde Pública do Porto do Rio de Janeiro, com demais órgãos sendo descentralizados para os municípios.

No Brasil pós-1822, o tema saúde pública aparece no relatório do ministro do Império, Nicolau Pereira de Campos Vergueiro (1778-1859), feito em 1832, publicado no ano seguinte. É de se supor que a saúde pública já fosse preocupação do governo independente constituído, entretanto não há relatórios (pelo menos não que tenham sobrevivido aos anos atuais) que o possam comprovar. Nesse documento, Vergueiro dá conta de inquietações governamentais com epidemias que já grassavam pelo mundo, como a cólera-morbo e a varíola, recomendando aos presidentes de província esforços suplementares para convencer a população a buscar a vacinação. ${ }^{5}$ Ele ainda sugeriu que fosse avaliada a proposta de instituição de Juntas de Saúde Pública em todas as províncias. Não há números sobre saúde pública neste relatório.

A instituição de uma Junta Central de Higiene Pública só seria criada no gabinete Monte Alegre, pelo Decreto ${ }^{\circ}$ 598, de 14 de setembro de 1850, concedendo ao Ministério dos Negócios do Império um crédito extraordinário de 200 contos para ser exclusivamente gasto no início dos trabalhos que visavam melhorar o estado sanitário da Corte e de outras povoações do Império. Pelo estabelecido no Decreto, a Junta seria "o centro dos estabelecimentos de igual natureza que existirem ou se criarem nas Províncias” (Brasil, 1851:299).

A preocupação em se criar um órgão para atacar diretamente a questão da saúde pública ${ }^{6}$ tem origem na entrada, em território nacional, de um inimigo do povo. Em 1849, vinda da cidade norte-americana de New Orleans, na Louisiana, chegava ao Rio de Janeiro a terrível febre amarela e vinha para ficar. A partir do ano seguinte já estava se manifestando, ceifando milhares de vidas, o que justificaria um contra-ataque governamental com a criação da Junta Central de Higiene Pública. Em 20 de setembro de 1851, o Decreto n 828 complementava o decreto anterior que criava a Junta Central de Higiene Pública.

Em 1853, o então presidente da Junta, o médico Francisco de Paula Candido, elaborou o Relatório sobre a salubridade da cidade do Rio de Janeiro em geral e a febre amarela em

5 Resta saber se haveria vacinas com a devida disponibilidade e na quantidade necessária. 0 documento não é claro neste sentido.

6 No caso, seria uma recriação do órgão instituído ao tempo do Príncipe Regente, agora com mais complexidade.

188 - Cadernos do Desenvolvimento Fluminense, Rio de Janeiro, N.7, pp. 185 - 204, jan./jun. 2015 
particular para subir à Augusta Presença de S. M. o Imperador, no qual defende reflexões curiosas e interessantes a respeito da higiene pública. Uma delas:

0 clima, isto é, o ar respirado pelos habitantes do Rio de Janeiro tem sofrido notável modificação com o crescimento da população e com as mudanças que a civilização tem operado em seus costumes. (Brasil, 1853)

Isto atesta a influência que os médicos europeus, teóricos sobre o assunto crescimento populacional, exerciam sobre seus colegas brasileiros.

Esse relatório tem data de $1^{\circ}$ de maio de 1853 e é acompanhado de "mapas" (tabelas) assinados por ele e por seu secretário, Herculano Augusto Lassance Cunha. É de se supor que ambos tivessem conhecimentos de demografia sanitária.

Para Paula Candido, o surgimento de doenças como a tuberculose, tifo, febre amarela etc. tem bastante influência das mudanças climáticas, conforme escreveu:

Estudar estas modificações e as causas inerentes às diferentes localidades do Império para corrigir ou ao menos atenuar seus perniciosos efeitos na saúde dos povos, tal é o fim principal, segundo entendo, da criação da Junta de Higiene. (Brasil, 1853)

Candido adverte que nem todas as Comissões Provinciais integrantes da Junta estavam criadas e instaladas, o que limitava o âmbito de seu relatório somente à Corte. Segundo ele, não era fácil avaliar a salubridade de uma cidade ou das causas que nela influem. Entre os fatores que pesam nesta avaliação estavam, em sua opinião:

\footnotetext{
A duração média do homem (a idade em que, termo médio, morre a população) bem como a proporção dos mortos para os vivos anualmente é um dado enganador para calcular a intensidade daqueles efeitos: a emigração, o aumento da reprodução, acompanhando algumas vezes 0 aumento da mortalidade, a idade das paixões, onde mais se morre, afluindo para as cidades, a vida efeminada e indolente da classe abastada, a idade provecta de alguns que pode ser mais que contrabalançada pela maior mortalidade da infância, são outros tantos elementos com que se deve contar para achar 0 índex da mortalidade, os quais, desatendidos, iludiriam a solução do problema. (Brasil, 1853)
}

Não deixa de causar um certo espanto o comentário sobre hábitos pouco ortodoxos (vida efeminada) da "classe abastada”, especialmente por se tratar do ano de 1853 e em um relatório dirigido ao Imperador. E mais ainda por ele arrolar esses costumes como uma das causas do excesso de mortalidade da população.

Candido prossegue seu relatório pedindo cuidados com “a atmosfera”, uma vez que, segundo ele, era pelo ar que os miasmas advindos de emanações orgânicas causavam principalmente males à saúde pública (Brasil, 1853). É possível admitir que Candido fosse um ambientalista avant la lettre, pois seu relatório continha claras preocupações com o meio ambiente da época. Ele estava pedindo o fim do despejo de imundícies em vias públicas, praias e rios, chamando a atenção do governo para a necessidade de encontrar formas de tratamento de dejetos humanos e animais que, quando expostos, contribuíam para tornar pestilento o ar respirável. ${ }^{7}$

Pelo menos o ar da capital da República devia ser bem pouco "respirável”. Era visível a falta de hábitos de higiene com que vivia a população de então. No aspecto das moradias populares a questão beirava o descalabro. $\mathrm{O}$ aumento populacional por que passou o Rio de Janeiro ao longo do século 19 foi decorrência da sua própria condição de capital, de centro

7 Ele apresenta no relatório um curioso cálculo sobre a quantidade de dejetos que eram produzidos diariamente na cidade. Tomando-se por base que cada homem excreta em média 165 gramas em fezes por dia, isto multiplicado pela população estimada em 266 mil habitantes perfaria 311.220 arrobas de matérias sólidas a se transformarem em gases fatalmente inalados pelas pessoas. Para animais, a estimativa dava conta de 155.610 arrobas a se volatizarem in natura diariamente. Ele aplicou cálculos de estimativas sobre a população do Rio encontrada por Haddock Lobo, em 1849 (p. 12). 
de poder. No final daquele século, o início da expansão do setor secundário da economia (ainda que de forma incipiente) coincidindo com o declínio da lavoura cafeeira e a libertação definitiva dos escravos agudizaria este processo. A decorrente alta demanda por moradias em contrapartida à reduzida oferta teria forte impacto sobre a população de baixa renda. Como as áreas centrais já abrigavam numerosas habitações populares, estas foram se degradando ainda mais com a chegada de novas levas de moradores. A edificação em que viviam 10 agora passaria a abrigar 50. Ou mais. Os cortiços ou "estalagens" floresceram neste período. Estes, por definição, eram

habitações coletivas, geralmente constituídas por pequenos quartos de madeira ou construção ligeira, algumas vezes instalados nos fundos de prédios e outras vezes uns sobre os outros; com varandas e escadas de difícil acesso; sem cozinha, existindo ou não pequeno pátio, área ou corredor, com aparelho sanitário e lavanderia comum. (Backeuser, 1906:105)

Ao que acrescentaríamos: sem nenhum esgotamento sanitário. O pior tipo de cortiço era a casa de cômodo - um prédio com divisões de madeira alugado a pequenas famílias ou a indivíduos solteiros e com as piores condições sanitárias possíveis. Qualquer administração que levasse a sério a saúde da população condenaria e atacaria este tipo de moradia que efetivamente minava a saúde da população e aumentava as estatísticas de doenças e óbitos. O primeiro administrador a se voltar contra este tipo de moradia foi, já na República, o prefeito Cândido Barata Ribeiro (1843-1910), que governou a cidade de 1892 a 1893. Como não poderia deixar de ser, ele era médico, chegou inclusive a ser lente catedrático da Faculdade de Medicina do Rio de Janeiro.

Para se ter uma ideia de quão significativos eram os números referentes a este tipo de moradia, em 1868 existiam 348 cortiços somente nas freguesias centrais (Sant'Ana, Santo Antônio, Santa Rita, São José e Sacramento), com exceção da área da Candelária. Deste total, 154 estavam localizados na freguesia de Sant'Ana. O total de moradores deste tipo de habitação chegava a 15.500. Somente na citada Sant'ana havia 6.458 moradores nestas condições (Carvalho, 1995:144). Para realçar esses dados, temos que, segundo informações referentes a 1870, o total da população da freguesia de Sant'Ana era de 32.686, o que significa dizer que de a cada cinco moradores de lá um vivia em cortiço (Lobo, 1978:360).

Em 1882, com o Decreto no 8.387, de 19 de janeiro, "atendendo à urgente necessidade de melhorar o serviço da Saúde Pública” (Brasil, 1882:1), foi instituído o regulamento para aquela Junta.

No Capítulo I, já estava estabelecido que a Junta Central de Higiene Pública manteria a sede na Corte, estendendo "suas atribuições a tudo quanto possa interessar à saúde pública, exercendo sua autoridade no mesmo município imediatamente e por intermédio das comissões sanitárias”, com representações (juntas de higiene provinciais) no Pará, Maranhão, Pernambuco, Bahia e Rio Grande do Sul e inspetores de higiene nas demais.

A Junta Central de Higiene Pública seria composta por nove membros efetivos, todos nomeados pelo governo - incluindo um presidente, um vice-presidente, um inspetor de saúde do porto e dois químicos doutores em Medicina - sete adjuntos, além de um número ilimitado de membros honorários (não estivesse no Império...).

Pelo regulamento, as Juntas Provinciais eram compostas por três membros, todos nomeados pelas presidências das províncias, assim como os inspetores de higiene. As comissões sanitárias nas províncias teriam um ou dois membros efetivos e um ou dois adjuntos, conforme a importância das paróquias onde serviriam. Os membros destas comissões seriam indicados a partir da Junta Central ou das Câmaras Municipais, com uma 
recomendação: "se estas [as Câmaras] tiverem médicos do partido, serão eles os preferidos para delegados ou presidentes das comissões".

O art. $9^{\circ}$ do regulamento traz uma informação de enorme importância: "A Junta Central de Higiene Pública terá para coadjuvarem na execução de seus trabalhos: um organizador da estatística demógrafo-sanitária, o qual será médico (...)” (Brasil, 1882:1, grifos nossos).

Foi a primeira vez que apareceu a expressão “estatística demógrafo-sanitária” em um relatório do Ministério dos Negócios do Império, a qual estava subordinada à questão da saúde pública. Antes de 1882, vários relatórios do ministro da vez apresentavam estatísticas da saúde, informadas em números ou apresentadas em quadros e "mapas". ${ }^{8}$ A partir de 1880, os mapas seriam assinados por um médico "encarregado da estatística” (Brasil, 1880). . Antes disso, não apareceu nenhum nome responsável pelas informações.

Entretanto, existem indícios de que houvesse algum médico especialista em estatística, uma vez que no relatório de 1878 falou-se inclusive em "expectativa de vida dos brasileiros".

A Junta Central de Higiene Pública foi desenvolvendo seus trabalhos, lutando contra as adversidades da melhor forma que pôde. Entretanto, os reveses não seriam poucos. No relatório enviado pelo presidente da Junta, José Pereira Rego (1816-1892), Barão do Lavradio, para ser incluído no que foi apresentado à Assembleia Geral Legislativa, na primeira sessão da $19^{a}$ Legislatura, pelo ministro do Império Meira de Vasconcellos, há queixas sobre as dificuldades enfrentadas pelo órgão central responsável pela higiene.

De outro lado, a Junta Central vê-se a cada momento embaraçada no desempenho dos seus deveres, de tal sorte que, quando quer propor ou executar uma medida sanitária que está na órbita de suas atribuições, não o pode conseguir por tornar-se preciso prévia satisfação, seja à Municipalidade, seja à Polícia, seja às inspetorias das repartições públicas e até à Faculdade de Medicina! Sem ambicionar uma independência absoluta de ação, sem aspirar a um estado no Estado, a Junta Central de Higiene pede uma independência relativa capaz de garantir-lhe o respeito mútuo nas suas relações, a observância exata de suas prescrições e 0 reconhecimento formal do seu caráter altamente científico. (Brasil, 1885:2)

Este grito por liberdade bradava contra o intervencionismo da burocracia da época. Mas adiante, o presidente parecia prever o futuro incerto da Junta: "temos a veleidade de fazer jus a alguma coisa em nosso favor; que os nossos esforços suspendam o desmoronamento da Junta Central” (Brasil, 1885:2).

E encerrava, de modo ufanista, o seu relatório:

É preciso confessar que só muito heroísmo e dedicação seriam capazes de alcançar estes resultados, através de tantas urzes, tendo que lutar contra tantos embaraços! Também é a nossa única glória... mas incontestável! Para comprová-la é bastante um só argumento; é a estatística. (Brasil, 1885:2)

Em seguida, exibiu os mapas preparados pelo “encarregado da estatística” Dr. Manoel Velloso Paranhos Pederneiras.

Com efeito, as suspeitas do diretor Domingos José Freire (1843-1899) tinham fundamento. Em 1886, a Junta Central de Higiene Pública foi extinta, sendo substituída pela Inspetoria Geral de Higiene (que englobaria também o Instituto Vacínico). ${ }^{10} \mathrm{O}$ novo órgão era formado por um inspetor e mais quatro membros, exercendo "a sua autoridade por si e por meio de delegados de higiene no município da Corte, e pelas Inspetorias ou inspetores de higiene e seus delegados nas províncias” (Brasil, 1886:86).

8 Como eles chamavam as tabelas.

90 que primeiro aparece é o "Dr. Luiz da Silva Brandão", assinando um mapa realizado em "maio de 1880", incluído no relatório do presidente da junta de higiene [Barão do Lavradio] sobre o estado sanitário durante o ano de 1879 apresentado ao governo em 1880.

100 Instituto Vacínico do Império foi criado por decreto imperial em 1846. 
Para que fossem cumpridas as suas atribuições, o novo órgão contaria ainda com um médico encarregado da estatística demógrafo-sanitária, quatro químicos, dois farmacêuticos e diversos desinfectadores. Foi instituída também a Inspetoria Geral de Saúde dos Portos, que deveria zelar pela principal entrada de endemias no território brasileiro: o porto do Rio e os das demais províncias do Império banhadas por mar ou rio.

Além das duas inspetorias, foi criado o Conselho Superior de Saúde Pública, "com a missão de consultar sobre as questões de higiene e salubridade geral em que o Governo precisar do auxílio de suas luzes" (Brasil, 1886:86). Este Conselho era composto pelos chefes das duas inspetorias recém-criadas e ainda pelo presidente da Academia Imperial de Medicina, do diretor da Faculdade de Medicina do Rio de Janeiro, dos cirurgiães-mores do Exército e da Armada "e de outros funcionários e profissionais competentes". ${ }^{11}$

Até aquele momento, só algumas províncias tinham algum setor responsável pela saúde pública (e, consequentemente, pelas estatísticas demógrafo-sanitárias). Segundo o relatório, a partir daquele momento, pelo menos no papel, todas as províncias teriam nas capitais inspetores de higiene, com delegados nas cidades e nas vilas mais importantes, havendo inspetorias compostas do inspetor e de dois membros, citando especificamente as capitais das províncias do Pará, Maranhão, Pernambuco, Bahia, São Paulo e Rio Grande do Sul.

As coisas pareciam seguir um novo rumo, pois, em 1886, o relatório do ministro do Império, Ambrosio Leitão da Cunha, Barão de Mamoré (1825-1898), exposto à Assembleia Geral, citou um "bem organizado boletim anual apresentado pelo médico demografista da Inspetoria Geral de Higiene" (Brasil, 1887:102), em que se pode comparar "as estatísticas da mortalidade" do Rio com diversas cidades da Europa.

No ano seguinte, o relatório anual do Ministério do Império já revelava notícias da saúde pública de todas as províncias, incluindo números estatísticos - o que vale dizer, produzidos pelas respectivas demografias sanitárias ou algo muito parecido.

O relatório referente ao ano de 1888 contém novidades inusitadas. A Inspetoria Geral de Higiene preparou e expediu questionários para serem preenchidos (e devolvidos) por estabelecimentos de instrução e educação (públicos e privados), hospícios, casas de saúde e prisões onde existissem alienados mentais, entre outros.

Entretanto, possivelmente a mais impactante revelação que traz o relatório do ministro do Império referente a 1888 foi a determinação que a Inspetoria Geral de Higiene:

mandasse proceder pelos respectivos delegados ao recenseamento da população de todos os cortiços existentes nas freguesias urbanas, com a maior discriminação possível, quanto aos habitantes: da naturalidade, sexo, idade, estado, profissão, designação da oficina ou casa de trabalho, renda proventos etc.; e quanto às habitações: da localidade e averiguação das condições higiênicas, com declaração motivada das obras indispensáveis, ou do que verificarem os delegados nos casos de serem absolutamente imprestáveis ou nocivas à saúde. (Brasil, 1889:144)

Infelizmente, tal recenseamento não saiu do papel. Seria extremamente útil para o governo da época e absolutamente inestimável para pesquisadores posteriores à época.

\section{Números para a República}

Caiu o Império, mudou o regime. Todavia, foi mantida a preocupação com a saúde pública. Afinal de contas, os bacilos e vírus das endemias não respeitam formas de governo,

110 relatório não explicita quais eram. 
atacando indiscriminadamente monarquistas e republicanos. Com o novo regime, a ação do federalismo se fez mostrar nas ações de sanitarismo, com a separação de âmbito governamental para a higiene terrestre e marítima. A primeira ficaria a cargo dos estados; a segunda caberia ao governo federal. No Rio de Janeiro, capital da República, foi criada, em 1890, a Inspetoria Geral de Higiene, com o setor de estatística ficando a cargo de um talentoso e estudioso demógrafo sanitarista: Aureliano Gonçalves de Souza Portugal. Em seu primeiro ano de trabalho, ele lançou o Anuário de Estatística Demógrafo Sanitária da Cidade do Rio de Janeiro, obra inédita sobre o assunto no Brasil.

Em 1893, a Inspetoria Geral de Higiene se transformou em Diretoria Sanitária, praticamente com as mesmas atribuições. Nesse momento, aparece, no cargo de auxiliar de demografista, um outro nome que seria uma legenda nas estatísticas brasileiras: José Luiz Sayão de Bulhões Carvalho. Mais tarde, com a saída de Aureliano Portugal, ele ocuparia o cargo de chefe da demografia do Instituto Sanitário Federal, órgão substitutivo da Diretoria Sanitária.

Em 1897, nova mudança de nome, mas não de atribuições naquela repartição. Agora, ela passaria a se denominar Diretoria Geral de Saúde Pública, ainda subordinada ao Ministério da Justiça e Negócios Interiores. Em 1903, chegou à DGSP um novo chefe, nomeado por indicação do próprio presidente Rodrigues Alves: o médico sanitarista Oswaldo Gonçalves Cruz, que manteve o setor de demografia sanitária sob a chefia de Bulhões Carvalho. A atuação deste setor foi fundamental na guerra empreendida por Cruz contra as endemias que faziam o Rio de Janeiro uma cidade doente. Isto pode ser comprovado pelo relatório que o sanitarista enviou ao ministro da Justiça, onde um trecho revela:

(...) a seção de isolamento e expurgo desinfetava sistematicamente, pela queima de enxofre e píretro, todas as casas que a Seção Demógrafo Sanitária, por suas estatísticas, indicava como focos de febre amarela na epidemia de 1902-1903 (...). (Cruz, 1904:7, grifo nosso)

Nesse mesmo relatório, Oswaldo Cruz passa a palavra a Bulhões Carvalho, que faz meticulosa descrição dos trabalhos realizados pelo setor sob sua responsabilidade.

A Seção de Estatística da DGSP existiria por longo tempo, sendo responsável, inclusive, pela publicação de um Boletim Mensal e um Semanal de Estatística Demógrafo-Sanitária. Além dessa repartição, de âmbito federal, havia uma Diretoria Geral de Polícia Administrativa, Arquivo e Estatística do Distrito Federal, fazendo parte do organograma da prefeitura da cidade. Nesta, pontificou Aureliano Portugal, desde que saiu da outra repartição.

\section{A polêmica do milhão}

Ao tempo do último recenseamento do século 19, realizado em 1900, já havia a expectativa da Capital Federal ter ultrapassado a casa do primeiro milhão de habitantes. Entretanto, os números encontrados naquele levantamento ficaram bem aquém, gerando alguma frustração. O censo, em sua parte relativa à cidade do Rio de Janeiro, acabou sendo anulado, visto o amontoado de falhas encontradas na sua fase de apuração. Na verdade, aquele próprio recenseamento não deveria mesmo ser levado em consideração, por conta de problemas graves e sérios na sua planificação e execução. Com o cancelamento, renasceu a esperança de a capital do país ter o tão sonhado milhão de habitantes. Caberia ao próximo recenseamento tão somente comprová-lo. 
A nova chance viria com o censo municipal, patrocinado pela prefeitura, a acontecer em 20 de setembro de 1906. Tal resultado tinha como objetivo suprir a falta de números atualizados do Distrito Federal, em consequência da lacuna aberta em 1900. Para a opinião pública, não havia o que duvidar: no máximo se discutiria quanto mais se tinha ultrapassado da casa do milionésimo habitante. Nas vésperas da data-base do censo de 1906, o jornal Gazeta de Notícias instituiu um concurso para que os leitores adivinhassem o número final encontrado pela apuração. Um deles abriu seu palpite, divulgando em carta dirigida ao jornal o seu prognóstico:

\footnotetext{
Sr. Redator - Não levo a minha imodéstia ao ponto de considerar-me incluído na lista dos que estão pilheriando a propósito do - Quantos somos nós?

Já lhe disse em carta e afirmo que pelas minhas pacientes tabelas nós somos 1.098.585 habitantes e para completar a notícia que lhe antecipei, venho por esta fornecer-lhe novos dados. (Gazeta, 23/9/1906, p. 6)
}

Na missiva, o leitor garantia o prognóstico com base nos "bons anos" que dedicava ao estudo de cadastros. Lamentavelmente, suas conjeturas foram debalde. Pelo resultado oficial, a população do Rio de Janeiro, em 1906, eram exatos 811.443 habitantes. Ainda não fora dessa vez.

As expectativas se voltaram, então, para o recenseamento geral seguinte, marcado para 1910, cumprindo o preceito constitucional que instituía censos decenais para o país. E as aspirações foram novamente frustradas, pelo cancelamento do recenseamento, determinado pelo então presidente Hermes da Fonseca. Só restava aguardar 1920, quando seria realizado o posteriormente conhecido como Censo do Centenário (Santos, 2004).

Em 1919, a imprensa, voz da opinião pública, clamava pela realização do censo e especialmente por números atualizados.

\footnotetext{
Os cálculos da nossa população são feitos por palpites, variando as opiniões em milhões de habitantes do país. Mesmo em relação à capital da República, não há mais do que suposições, destituídas de bases sólidas de cálculo. (O Paiz, 3/8/1919, p. 3)
}

Nesse clima de "suposições" sobre os verdadeiros números da população em que se encontrava o Brasil havia espaço para toda a sorte de controvérsias. Mas, com tudo isso, há uma pergunta que não quer calar:

\section{Por que era tão importante ter um milhão de habitantes?}

Pelo senso prático, nem era tão importante assim, ao contrário. Quanto mais populosa se torna a cidade, de forma inversamente proporcional piora a qualidade de vida de seus habitantes. E mais: o Rio de Janeiro, com seu relevo característico, aliado às várias extensões de terrenos brejosos que possuía, certamente teria problemas crescentes de natureza ambiental e de infraestrutura. Consequentemente, haveria reflexos na saúde pública. Em 1853, Francisco de Paula Cândido, médico de D. Pedro II, fez extenso relatório dirigido ao Imperador, pedindo pelo fim do despejo de imundícies em vias públicas, praias e rios chamando a atenção do governo para a necessidade de se encontrarem formas de tratamento de dejetos humanos e animais, que, quando expostos, contribuíam para tornar pestilento o ar respirável. Mesmo com algum possível saneamento básico realizado no período, não há registro de que nas primeiras duas décadas do século 20 tenha sido encontrada solução para 
os problemas levantados por Cândido. Com o aumento da população para a casa dos sete dígitos, a situação tenderia a piorar.

Então, qual a razão do anseio incontido pela obtenção desse número "mágico" - o milionésimo habitante da cidade? É de se crer que seja por absolutas razões provincianas. Parecia que a capital do Brasil só seria respeitada se sua população ultrapassasse a casa do milhão. O provincialismo de então mirava com olhos de inveja as cidades europeias que já tinham alcançado aquela marca e o inconformismo ganhava tônus ao se saber que na América do Sul já havia pelo menos uma cidade com mais de um milhão de habitantes - exatamente a "rival" Buenos Aires. Desde o censo argentino de 1909 sabia-se que a população da capital platina já tinha ultrapassado o ansiado número, atingindo a marca de 1.231.698. Destes, grande parte eram estrangeiros, uma vez que um considerável fluxo de emigrantes estava direcionado para lá desde o final do século 19.

Só no mundo ocidental, nove cidades ${ }^{12}$ já tinham atingido aquela cifra "invejável”. Desta forma, virou questão de honra para a opinião pública do Rio de Janeiro a obtenção de números que atestassem a chegada da população ao tal número "mágico". Era como se fosse uma condição sine qua non para ser considerado como um país "civilizado" - ter uma capital com mais de um milhão de habitantes. Para os brasileiros de então, acostumados a mirar nos exemplos do hemisfério norte, ter o respeito das nações desenvolvidas passava pela aparência de cosmopolitismo que uma capital fartamente populosa poderia ostentar. Está bem claro que o país mantinha os olhos fixos na Europa, como se pode constatar pela reflexão de Lucia Lippi Oliveira:

\footnotetext{
Nos anos 20, houve uma reavaliação tanto da Europa quanto do Brasil. Havia várias Europas, uma delas vista como ultrapassada e decadente, à qual o Brasil parnasiano estaria ligado. Outro mundo europeu era representado pelos movimentos de vanguarda que rompiam com os valores clássicos e que apelavam para as forças do inconsciente, para forças primitiva, mitológicas. (Oliveira, 1990:180)
}

Neste contexto, estava muito claro que a imprensa e a intelectualidade brasileiras se ressentiam da herança de "país dos botocudos", que não conseguia o cosmopolitismo aparente de uma capital com mais de um milhão de habitantes em pleno século 20, situação bastante piorada por não conseguir realizar um censo que lhe desse a certeza disso.

Exatamente no auge dessas incertezas o Rio de Janeiro acompanhou uma polêmica entabulada pelo vespertino A Noite e um demógrafo sanitarista, chefe da Seção de Demografia da Diretoria Geral de Saúde Pública. A famosa "polêmica do milhão" iniciou quando, na coluna "Ecos e novidades", de A Noite, de 29 de setembro de 1919, escreveu o articulista anônimo:

\footnotetext{
Quando, há mais de dez anos, o prefeito Passos mandou fazer o recenseamento da população do Distrito Federal, os dados apurados deram pouco mais de 91113 mil habitantes, sendo cerca de 700 mil só para a zona urbana. Baseado ainda nestes dados, os últimos oficialmente reconhecidos, o 'Boletim da Estatística Demógrafo Sanitária’, bem impressa publicação da Diretoria Geral de Saúde Pública, faz em todos os números um cálculo aproximado da população do Rio, de acordo com certos métodos científicos já consagrados. E por estes métodos, em que entram os excessos da natalidade sobre a mortalidade e o das entradas sobre saídas pelas vias terrestres e marítimas etc., a população do Rio vem oscilando entre 930 e 950 mil, sem chegar jamais ao desejado milhão.
}

12 Buenos Aires, Chicago (2.185.283 habitantes, em 1910), Nova lorque (já a maior do mundo em 1910, com 4.766 .883 habitantes), Filadélfia (1.549.008 hab., em 1910), Berlim (2.071.257 hab., em 1910), Bruxelas (1.026.454 hab., em 1910), Londres (4.521.685 hab., em 1911), Paris (2.843.094 hab., em 1911) e Viena (2.031.498 hab., em 1910). Fonte: BRASIL. Recenseamento do Brasil realizado em 1 de setembro de 1920. População do Rio de Janeiro, vol. II, $1^{\text {a }}$ parte. Rio de Janeiro: Tipografia da Estatística, 1923. p. XXX/XXXI.

13 Provavelmente saiu com erro de revisão. Posteriormente o jornal admitiu como número correto 811 mil habitantes. 
Longe de nós a pretensão de condenar processos científicos consagrados pela convenção ou por consenso unânime dos técnicos. Mas, francamente, neste caso da população do Rio, os tais métodos ou processos de calcular adotados pelas nossas autoridades da Estatística Demógrafo Sanitária parecem não valerem nem meio caracol. (A Noite, 29/09/1919, p. 2).

Esta era uma acusação bastante séria. Afinal de contas, um órgão de imprensa estava utilizando suas páginas para duvidar dos métodos admitidos como científicos da Diretoria Geral de Saúde Pública (DGSP), que aplicava cálculos estatísticos aos registros administrativos coletados.

$\mathrm{Na}$ matéria, o articulista lembrava que bairros novos surgiram e estavam sendo ocupados (Copacabana, Ipanema), assim como novas ruas foram abertas em antigos bairros cuja ocupação crescia significativamente (Engenho Velho, Vila Isabel) e que mesmo assim era conhecido o déficit de habitações por que passava a cidade.

Outro argumento levantado pelo autor do artigo foi o perceptível aumento no tráfego de pessoas nas principais artérias da cidade, especialmente nas tardes de sábado. Além disso, como prova do considerável aumento da população, havia, segundo ele, o significativo acréscimo na produção de carne verde, que dobrara em poucos anos.

E apesar de tudo isto, o tal 'Boletim da Estatística Demógrafo Sanitária' insiste, de acordo com os tais processos científicos, em garantir que a população do Rio continua estacionária, quando não afirma que diminuiu, como já tem acontecido várias vezes. ${ }^{14}$

Um método que dá resultados tão evidentemente falhos já não deveria ter sido abandonado? Valerá a pena que todos os trimestres a Imprensa Nacional se esmere na confecção de um boletim tão flagrantemente falho, pelo menos em relação a esta parte da população da capital? (A Noite, 29/09/1919, p. 2)

Percebe-se claramente o desdém com que o articulista trata dos "tais processos científicos”. Normalmente, se rebatem argumentos científicos com outros argumentos também científicos, bem embasados, bem metodizados. E $A$ Noite o fez, em sua edição de 4 de outubro, na mesma coluna "Ecos e novidades", acusando o recebimento da resposta do médico demografista, e, em seguida, apresentando a sua tréplica:

O Rio ainda não tem um milhão de habitantes?

O Sr. Dr. Sampaio Vianna, diretor do Serviço Demógrafo Sanitário, em carta que nos escreveu há dias, e baseado em cálculos científicos adotados pela sua repartição, afirma categoricamente que não. Na sua opinião a população do Rio, que segundo o recenseamento Passos ${ }^{15}$ era, em 1906, de pouco mais de 811 mil habitantes (...) deve ser atualmente orçada em 915.875 habitantes. (A Noite, 4/10/1919, p. 2)

A Noite continuou insistindo que os números de Sampaio Vianna estavam incorretos, "não se assentando em base sólida". A seguir, os argumentos do articulista.

Em 1906, quando o Rio tinha pouco mais de 811 mil habitantes, o número de prédios no Distrito Federal era de 82.396. Dando-se a cada prédio a média de dez moradores, obtém-se o resultado de 823.960 habitantes, número bem aproximando do resultado recenseado, o que prova que a média é regular.

Na Prefeitura não puderam nos fornecer o número de prédios novos, edificados em 1918. Deram-nos, porém, os algarismos referentes aos anos anteriores, que são os seguintes, no decênio de 1907 a 1917: 1.717, 1.796, 2.198, 2.318, 3.189, 4.202, 3.928, 1.849, 1.016, 3.577 e 1.272. Total: 27.064 .

Somando-se esse total ao apurado em 1906 têm-se 109.460 prédios. Dando-se-lhes a mesma média de dez moradores, têm-se 1.094.460 habitantes.

14 Efetivamente a população do Rio diminuiu em fins de 1918, quando se abateu sobre a cidade a pandemia da gripe espanhola. Os números daquele ano atestam (com razão) que morreram mais pessoas do que nasceram. Pelo menos quanto a este argumento, $A$ Noite errou.

150 jornalista denominou assim o recenseamento feito no Distrito Federal, em 1906, por ordem do então prefeito Pereira Passos, para substituir os dados cancelados do Censo de 1900.

196 - Cadernos do Desenvolvimento Fluminense, Rio de Janeiro, N.7, pp. 185 - 204, jan./jun. 2015 
Há, porém, circunstâncias muito interessantes a acrescentar. Em primeiro lugar, a de que não havia, em 1906, a tremenda crise de casas que existe atualmente.16 Crise essa que motivou o costume agora adotado das famílias de poucos recursos sublocarem um ou vários cômodos das casas em que residem, procurando, assim, atenuar o aumento exagerado do aluguel. Esse costume autorizaria o aumento da média de dez moradores por casa.

Mas a circunstância mais interessante é a de que naquele total não entraram os novos prédios de 1918 e 1919, que devem ser calculados, pelo menos em três mil, com 30 mil habitantes, que elevariam, assim, a população a mais de um milhão e cem mil habitantes.

Modéstia à parte, quer nos parecer que esse processo de calcular é mais simples, mais claro e mais seguro que os adotados pela Demografia Sanitária. (A Noite, 4/10/1919, p. 2)

Na resposta a Sampaio Vianna, vale destacar, além da forma apaixonada com que o articulista defendeu seus argumentos, a informação sobre a média de ocupação de uma residência: dez pessoas! E que, em média, uma moradia abrigava duas ou mais famílias. A residência só não constituía mais de um domicílio por ter somente uma cozinha e todas as refeições serem preparadas no mesmo cômodo. Não deixa de ser uma informação interessante para demógrafos, assim como para geógrafos que estudam, historicamente, o uso e a ocupação espacial.

$\mathrm{Na}$ argumentação do jornalista, percebe-se a aguilhoada nos números da DGSP utilizando, segundo asseverou, números oficiais fornecidos pela Prefeitura. Tinha-se, então, uma polêmica embasada em dados oficiais dos dois lados!

No dia 9 de outubro, $A$ Noite dava prosseguimento à polêmica. $\mathrm{O}$ anônimo articulista insistia em que, "pelos seus cálculos", era possível garantir que o Rio tinha mais de um milhão de habitantes. Ele cita a carta recebida de Sampaio Vianna contestando aquela informação e asseverando que a cidade "não possui mais de $945.675^{17}$ habitantes". O jornalista garantiu que responderia a estes cálculos "logo que tenhamos completos os dados que a respeito estamos coligindo (A Noite, 9/10/1919, p. 2)

Ou seja: A Noite tinha efetuado operações matemáticas e entabulado estimativas e se transformado em órgão produtor de estatísticas! E mais: o articulista estava invocando o testemunho do diretor geral de estatística da União, Bulhões Carvalho, cujos cálculos davam para o Rio "1.166.540 almas". Fechando a matéria, ele pergunta se os métodos do órgão oficial de estatística seriam menos científicos e menos seguros que os do demografista da Saúde Pública. Em seguida, passou a palavra ao chefe da Seção de Demografia, que não se fez de rogado e eriçou lanças na direção do jornal:

\footnotetext{
Sr. Redator - Uma vez que A Noite, em seu 'eco' de sábado, confessa 'não saber quais os processos adotados pela demografia sanitária carioca para calcular a população do Rio de Janeiro’, e ainda mais, levanta a suspeita de se não assentarem em base sólida os cálculos realizados por esta repartição, vejo-me na contingência de vir vos explicar (...).

O método que adoto desde 1906, quando pude dispor de base segura, (...), é o de Maurice Block, que, à página 427 do seu 'Tratado de Estatística', aconselha que 'à défaut de recensement et dans l'intervalle de deux opérations, oú établit la difference entre les naissances et les décés, en défalquant de cette difference l'excédent de l'emigration. ${ }^{18}$

Aplicado ao Rio de Janeiro esse processo, sabendo-se que, de setembro de 1906 a agosto de 1909, nasceram nesta capital 336.862 indivíduos, faleceram 276.973 pessoas, entraram por vias marítima e terrestre 24.945.733 e saíram pelas mesmas vias 24.901.390 passageiros, obtém-se o seguinte resultado: população do Rio de Janeiro em setembro de 1906, 811.443; excesso dos nascimentos sobre os óbitos, de $1^{\circ}$ de outubro de 1906 a 31 de
}

16 Não é verdade. Com o "Bota-abaixo" de Pereira Passos houve, sim, uma crise de moradias para abrigar os que foram expulsos pelas demolições. 17 Destaque-se que este é um número diferente do que consta na carta de Sampaio Vianna divulgada no dia 4/10/1919.

18 "à falta de um recenseamento e no intervalo de duas operações, onde estabelecer a diferença entre os nascimentos e os falecimentos, deduzindo ou subtraindo dessa diferença o excedente da emigração sobre a imigração, ou lhe agregando ou somando, se for o caso, o excedente da imigração". Em equação seria: nasc - falec - excedente (emigr - imigr); nasc - falec + excedente (imigr - emigr). [tradução nossa] 
agosto de 1919 (336.862 menos 276.973), 59.889. Excesso das entradas sobre as saídas por vias marítima e terrestre, de $1^{\circ}$ de outubro de 1906 a 31 de agosto de 1919 (24.945.733 menos 24.901.390), 44.343. População em 31 de agosto de 1919, 915.675.

É bem possível, Sr. Redator, que o Método de Block, dado o grau de cultura de uma parte de nosso povo, que ainda não compreendeu a necessidade do registro civil de nascimentos, tenha um de seus elementos incompletos; mas ainda assim é ele o único método capaz de nos fornecer um algarismo aproximado da verdade. (A Noite, 9/10/1919, p. 2).

O médico demografista prossegue em sua carta, citando suas fontes: estradas de ferro Central do Brasil, Rio do Ouro e Leopoldina; companhias de navegação Cantareira e Teresópolis e Inspetoria de Polícia dos Portos, sendo que para esta última fez a ressalva de que frequentemente a DGSP devolve boletins de informação quando são detectadas irregularidades "por circunstâncias que não vêm ao pêlo (sic) citar".

Quanto aos números divulgados anteriormente pelo articulista, como sendo "da Prefeitura”, Sampaio os refuta veementemente, lembrando que muitos dos prédios citados como novos foram construídos em terrenos onde se demoliram outros. Isto caracterizaria uma dupla contagem. Como exemplo, ele cita o próprio prédio da Saúde Pública, muito provavelmente contado entre os construídos após 1906, e que foi edificado em terreno onde havia vários outros, certamente incluídos nos “82.396 prédios" apontados pelo recenseamento municipal, e que foram ao chão posteriormente para a construção do edifício da Saúde Pública. Não satisfeito com a demonstração, lançou o desafio:

Se a redação d'A Noite me provar que existem no Rio de Janeiro 109.460 prédios, dando as mãos à palmatória, abandonarei o processo que sigo. (A Noite, 9/10/1919, p. 2)

Ao fim de sua carta, Sampaio Vianna ainda se permitiu uma blague, assegurando que o Método de Block adotado por ele era "mais seguro" que o apresentado pelo vespertino.

A falta de um censo recente suscitava toda aquela celeuma, em assunto que mexia com os brios e com a autoestima dos cariocas de então. Mas a polêmica ainda não acabara.

O articulista de $A$ Noite citara dados informados por Bulhões Carvalho, então à frente da Diretoria Geral de Estatística, que era o órgão mór oficial da estatística do Brasil, responsável pela realização dos recenseamentos brasileiros desde o tempo do Império. Era evidente que o lado para onde Bulhões pendesse teria o respaldo da ciência e dos números oficiais.

Àquela altura, um outro jornal também queria participar da "polêmica do milhão". O jornal O Paiz, entrou na discussão concordando com seu concorrente e invocando dados que teriam sido publicados pelo titular da DGE.

A população do Distrito Federal tem sido objeto dos comentários por parte da imprensa, empenhada em saber se ela já atingiu ao desejado milhão de habitantes.

A respeito do assunto, julgamos interessante transcrever algumas informações publicadas pelo Dr. Bulhões Carvalho, conhecedor do assunto, segundo as quais o Rio conta com 1.166.540 habitantes aproximadamente.

É certo que não há dados seguros a respeito, mas o resultado obtido pelo Dr. Bulhões Carvalho deve estar muito próximo de um número exato de habitantes, como é fácil verificar.

De 1880 a 1890, o acréscimo da população foi de 163.101 habitantes; de 1890 a 1900, de 168.914; de 1900 a 1906, de 120.777, e de 1906 a 1912, de 163.476.

Ora, se em 1906 a população do Rio de Janeiro era de $812.342^{19}$ e em 1912 de $975.818,{ }^{20}$ houve um acréscimo anual médio de 27.246 habitantes; multiplicando este número por sete há um total de 190.722 que, adicionados aos 975.818 dão 1.166 .540 .

19 Número incorreto. Como visto, a população apurada para o Rio de Janeiro em 1906 foi 811.443 habitantes.

200 articulista não citou a fonte de onde tirou este número.

198 - Cadernos do Desenvolvimento Fluminense, Rio de Janeiro, N.7, pp. 185 - 204, jan./jun. 2015 
Além disso, tendo o Rio de Janeiro cerca de cento e dez mil casas, sua população deve ser de 1.100.000 habitantes; mas atendendo-se a que se tem aberto muitos e grandes hotéis, todos cheios, e a que muitas famílias têm sublocado parte de suas habitações, pode a população ser calculada em 1.200.000 habitantes. (O Paiz, 9/10/1919, p. 3)

Tendo sido citado em dois jornais, como detentor de números tão entusiásticos, o diretor da DGE encaminhou carta aO Paiz, publicada na nota "A população da capital”, dois dias depois:

A propósito do que escrevemos sob este mesmo título, anteontem, recebemos a seguinte carta do diretor geral de estatística:

'Num dos interessantes sueltos de ontem, O Paiz atribuiu-me um cálculo que não me recordo ter feito, relativamente à população do Rio de Janeiro. Deixaria passar despercebida a referência, se dela não se aproveitasse o apreciado vespertino A Noite para contestar a criteriosa avaliação do Dr. Sampaio Vianna nos boletins de estatística demógrafo-sanitária. Nas informações que tenho tornado públicas, jamais precisei em 1.166.540 o número dos cariocas.

No Anuário publicado pelo Instituto Sanitário Federal, em 1895, não havendo base censitária exata, calculei aproximadamente em 600.000 o número de habitantes da área urbana e em 150.000 o número de habitantes da zona suburbana; avaliando em cerca de 750.000 almas toda a população do Distrito Federal. Nos Anuários editados mais tarde, em 1903, 1904 e 1905, pela Diretoria Geral de Saúde Pública, ainda por falta de dados censitários, tive que orçar a população urbana entre os limites de 800.000 e 872.000 , continuando a avaliar em 150.000 a da zona suburbana e rural, ou pouco menos ou pouco mais de um milhão de habitantes na totalidade do Distrito Federal.

Convidado a colaborar no recenseamento municipal mandado executar pelo prefeito Passos, em 1906, verifiquei que eram exageradas aquelas estimativas, adotando, daí em diante, nas publicações feitas sob minha responsabilidade os resultados do referido censo como elemento básico dos cálculos demográficos. É o que se pode verificar nos Anuários e Relatórios da Diretoria Geral de Estatística, dados à publicidade nestes últimos tempos, onde se encontram, em relação ao Rio de Janeiro, exatamente reproduzidos os algarismos da Repartição de Saúde Pública, isto é, apurados pelo mesmo processo a que recorreu o Dr. Sampaio Vianna, de acordo com os conselhos de Block, mestre no assunto. Tanto eu como o Dr. Sampaio Vianna acreditamos que a população do Rio de Janeiro, atualmente, deve atingir ou mesmo exceder um milhão de habitantes, mas a confirmação desse juízo depende, necessariamente, de um recenseamento bem feito. Por enquanto, parecem aceitáveis os algarismos constantes dos boletins demográficos da Diretoria de Saúde Pública.

Muito grato pela generosidade das referências com que me têm distinguido a ilustre redação d'O Paiz, sou, com alta estima etc. Bulhões Carvalho’. (O Paiz, 11/10/1919, p. 4)

Nesta resposta de Bulhões Carvalho percebe-se algo que faria toda esta celeuma cessar, celebrando um "empate". Os "estatísticos" de A Noite e d'O Paiz asseguravam que a cidade já tinha um milhão de habitantes. O diretor da DGE afirmava que tanto ele quanto seu colega, Sampaio Vianna, acreditavam na possibilidade da cidade ter efetivamente ultrapassado o seu milionésimo habitante, apenas não tinham a confirmação que só os números de um censo bem feito poderia dar. Curiosamente, os números citados tanto pelo vespertino $A$ Noite, quanto pelo matutino $O$ Paiz estavam muito próximos do efetivamente apurado no Censo de 1920. O "Método de Block” estaria errado? Certamente que não, mas se os cálculos baseados nele apresentavam defasagem maior que os efetuados pelos "estatísticos" dos citados jornais, é possível imaginar que os principais suspeitos sejam os números com que uns e outros tivessem trabalhado. Não percamos de vista o fato de que o registro civil da época era irregular, incompleto, passível de erros. O mesmo vale para os demais registros administrativos, como o número de imóveis residenciais da cidade, por exemplo. Assim como um condimento estragado faz desandar um prato, por mais suculento que ele possa parecer, números defeituosos tornam rançosa qualquer estatística. 


\title{
6. Fim de caso
}

Mas a polêmica não parou ali. Um dia antes da resposta do titular da DGE, $A$ Noite prosseguiu com seu martelo sobre o ferro quente do debate a respeito dos verdadeiros números da população carioca:

\begin{abstract}
O Rio tem mais de um milhão de habitantes. Depois da infeliz réplica do Sr. Sampaio Vianna, já não pode haver a menor hesitação nessa afirmativa. (...) O Sr. Dr. Sampaio Vianna prometeu que se a redação d'A Noite lhe provasse que existem no Rio de Janeiro 109.460 prédios, dando as mãos à palmatória, abandonaria o processo que segue. Pois pode dar as mãos à palmatória e abandonar o tal processo. Como poderíamos provar o número de prédios do Rio? Contando-os um a um? Claro que não. A única base são os dados oficiais da Prefeitura. Pois para estes dados, podemos garantir que o número de "prédios novos" construídos no Rio, de 1906 até fins de 1918, foi de 25.308, que, somados aos 82.396 de 1906, dão um total de 107.784. Ainda não são os 109.460 que o Sr. Sampaio Vianna quer. Faltam 1.676. Mas é conveniente lembrar que estamos no fim de 1919 e que com o desenvolvimento que têm tido as construções este ano, esse número 'muito inferior ao de outros anos passados', deve ter sido de muito excedido. (O Paiz, 11/10/1919, p. 4)
\end{abstract}

O articulista acrescentou duas circunstâncias, no seu dizer, interessantes: os prédios construídos foram destinados a servir como moradia; a partir de 1906, edificaram-se no Rio grandes hotéis e robustas casas de cômodos, onde residiram numerosas famílias.

Em resumo, de acordo com os dados oficiais da Prefeitura, e com a média de dez moradores para cada prédio, aceita pela demografia sanitária, a população do Rio, em fins de 1918 deve ser computada em 1.077.840 habitantes - no mínimo... (O Paiz, 11/10/1919, p. 4)

A carta enviada por Bulhões Carvalho a $\mathrm{O}$ Paiz, dando conta de que confirmação de conjeturas só com a efetivação do novo censo, deveria por termo àquela polêmica, mas há que se reconhecer, o articulista d'A Noite não se entregava facilmente. Entretanto o golpe de misericórdia veio em seguida, por meio de carta do demógrafo sanitarista da Saúde Pública, publicada na edição do dia 15 do vespertino. Embora longa, vale a sua transcrição como registro histórico:

'O Rio não tem um milhão de habitantes! As afirmações do médico demografista da saúde pública'

Tendo obtido as informações que desejava, O Sr. Sampaio Vianna, médico demografista da Saúde Pública, dirigiu-nos a seguinte carta, a que responderemos logo que tenhamos, por nossa vez, os dados positivos em que possamos apoiar em definitivo a nossa opinião, dando fim a uma controvérsia (...) que nada tem de pessoal.

'Sr. Redator - No ‘Eco' de sexta-feira, a propósito ainda do cálculo da população do Rio de Janeiro, insiste $A$ Noite em afirmar que havia nessa cidade, no ano próximo passado, 107.781 prédios (...)

Se relerdes, com atenção, minha carta de 8 do corrente, verificareis que não me referi a prédios 'reconstruídos', e muito menos a 'consertados e modificados'. O que disse e hoje afirmo (...) é que, dentre as casas novas construídas de 1906 a 1918, estão incluídas muitas que substituem 'outras demolidas' e 'já contadas no censo de 1906, dentre as 82.396', então arroladas.

(...) inúmeros são os exemplos (...) que mostram que os algarismos 107.784 não exprimem a verdade.

Antes de transcrever a carta que, em resposta à consulta que lhe dirigi, me enviou o Dr. Aureliano Portugal, provecto diretor da Estatística Municipal, repartição que forneceu À Noite a estatística domiciliar com que se pretende demolir os cálculos feitos pela seção que dirijo, preciso, ainda, fazer um comentário com que essa redação antecedeu à publicação de minha última carta.

Não é verdade que o Dr. Bulhões Carvalho, cuja autoridade pretendestes contrapor à minha humilde pessoa, tenha avaliado a população do Rio em 1.166.540, como podeis verificar pela resposta por ele dada no suelto d'O Paiz. O eminente diretor de Estatística não só não fez semelhante cálculo, como ainda mais, declara lhe parecerem aceitáveis os algarismos constantes dos 'Boletins Demográficos da Saúde Pública'. Bem sabíamos que o Dr. Bulhões Carvalho não podia endossar uma operação que aberra de todos os preceitos científicos, pois ela admite uma mesma taxa de crescimento para 1906 a 1912, época de prosperidade, em que a população foi crescendo, como para 1913 a 1918, período de crise econômica e financeira (...).

Eis a carta do Dr. Aureliano Portugal:

200 - Cadernos do Desenvolvimento Fluminense, Rio de Janeiro, N.7, pp. 185 - 204, jan./jun. 2015 
'Prefeitura do Distrito Federal - Diretoria de Estatística e Arquivo, em 11 de outubro de 1919 - Sr. Dr. J.F. de Sampaio Vianna m.d. Médico demografista - Em resposta ao apelo que dirigistes à seção municipal de estatística, quanto às dúvidas suscitadas pelo jornal $A$ Noite, em relação ao cálculo da população do Rio, devo responder:

- os dados relativos às construções licenciadas constam de mapas insertos nas mensagens do prefeito, reproduzidos de relatórios da Diretoria de Obras.

- 82.395 foram os 'prédios' encontrados, em 1906, em condições de serem habitados, figurando ao lado deles, no mapa, então publicado, os 'domicílios' - 80.645 particulares e 3.041 coletivos.

Não sendo coligidos para fins estatísticos por aqueles dados não se pode conhecer com precisão a superfície nova realmente 'coberta' em cada ano. Se as reconstruções 'figuram' discriminadas nos quadros que $A$ Noite conhece, 'nos casos dos prédios a construir em terrenos resultantes de abertura de ruas, são as respectivas licenças, em geral, contadas como novas edificações, embora em substituição a outras tantas demolidas ou desapropriadas'.

No cálculo d'A Noite 'não se atendeu para os prédios demolidos e arruinados no período em questão', como não se obedeceu ao coeficiente da densidade da população, determinado em 1906 (pág. 34 do $1^{\circ}$ volume publicado). Outra consideração a fazer é o caráter das modernas 'avenidas', em avultadíssima quantidade nos últimos anos, compostas de grande número de prédios que não comportam, entretanto, famílias muito numerosas. Autorizando a fazer uso desta como convier, subscrevo-me etc. Aureliano Portugal'. (A Noite, 15/10/1919, p. 2)

Embora tenha escrito que responderiam "logo que tenhamos, por nossa vez, os dados positivos”, A Noite não mais tocou no assunto. Uma vez realizado o Recenseamento Geral de 1920, foi apurado para a cidade o total de 1.157.873 habitantes naquele ano. Com este número e mais o levantado no recenseamento municipal de 1906 (811.443) seria possível calcular as taxas de crescimento anual da população da cidade entre os dois anos.

Em tempo: o Rio de Janeiro cruzou a barreira do sonhado milhão de habitantes em 1915! (Brasil, 1923). ${ }^{21}$ Isto significa que a cidade levou, desde a sua fundação, em 1565, exatos 350 anos para atingir o seu milionésimo habitador. Para chegar ao segundo milhão levaria apenas 31 anos. ${ }^{22}$ Mas isto é uma outra história...

Tanto na Diretoria Geral de Estatística, quanto nos órgãos municipais onde se fazia o controle das estatísticas vitais, os demógrafos sanitaristas pontificaram e se envolveram em outras polêmicas. Eles tinham a ciência ao seu lado.

Com a criação do IBGE e do Sistema Estatístico Nacional proposto por Teixeira de Freitas (1890-1956), gradativamente a ação dos demógrafos sanitaristas foi perdendo espaço para a dos estatísticos. Até que finalmente as tabulações de estatísticas vitais ficaram exclusivamente sob a responsabilidade do novo sistema. Uma das publicações onde os demógrafos sanitaristas apresentavam os resultados de seus trabalhos com as estatísticas vitais, o Boletim de Estatística Demógrafo Sanitarista do Município do Rio de Janeiro, criado em janeiro de 1903, na Diretoria Geral de Saúde Pública - DGSP, sob a direção de Oswaldo Cruz, teve seu último número publicado em janeiro de 1940. O mesmo boletim feito no Estado de São Paulo ainda duraria um pouco mais, até o início dos anos 1950.

No esquema proposto por Teixeira para o Instituto Nacional de Estatística (primeiro nome do IBGE), as estatísticas de vida, morte e saúde pública estavam incluídas nos "aspectos intrínsecos" da demografia dinâmica, no grupo "Situação demográfica". Já a assistência médico-sanitária estava incluída no "Bem-estar físico-social" da parte "Situação social". Tais números foram inseridos no Anuário Estatístico do IBGE, publicado em 1936.

De 1955 a 1964, com o nome de Estatísticas do Registro Civil, os dados antes

$21 \mathrm{Na}$ taxa calculada pelo processo geométrico, estimou-se que a população do Rio seria de 1.023.993, em 1915. Utilizando a fórmula de Wappaeus para calcular a taxa de crescimento o número obtido para este ano foi 1.021.114. Na taxa de crescimento calculada pelo processo aritmético, a cidade já tinha, desde 1914, o seu milionésimo habitante (1.017.126).

22 Segundo estimativas do IBGE, em 1946, a população da cidade teria aproximadamente 2.014.200 habitantes. Cf. IBGE. Anuário Estatístico do Brasil. Ano IX - 1948. Rio de Janeiro: IBGE, 1949. p. 43. 
arrolados pelos demógrafos sanitaristas eram de responsabilidade do Serviço de Estatística Demográfica, Moral e Política - SEDMP, do Ministério da Justiça. A partir de 1974, o IBGE assumiu os encargos de coletar, sistematizar e divulgar os dados remetidos pelos Cartórios do Registro Civil de Pessoas Naturais, apresentando tabelas por Unidades da Federação, capitais, áreas metropolitanas, microrregiões homogêneas e por todos os municípios brasileiros para nascidos vivos, casamentos, óbitos e óbitos fetais (desde 1984, também sobre separações judiciais e divórcios), o que faz até os dias atuais.

Estas estatísticas não têm o detalhamento que os demógrafos sanitaristas faziam, especialmente quanto às endemias e causa mortis, por serem dados retirados dos registros cartoriais. Ao tempo deles, a coleta se fazia nos hospitais e ambulatórios com o fito específico de auscultar as condições sanitárias da população. Todavia, com a estrutura montada para o IBGE, inicialmente envolvendo os órgãos colegiados, posteriormente com a coleta sistematizada feita pelo próprio Instituto, já não havia mais necessidade de médicos se especializarem em estatística. De qualquer forma, a importância daqueles médicos, que cuidavam também da saúde dos números estatísticos, estava indelevelmente marcada na História das Ciências.

\section{Conclusão}

A importância dos demógrafos sanitaristas para as ciências estatísticas é inegável e a militância deles nesta seara se deu quando não havia cursos universitários de Estatística. De forma geral, eram todos estudiosos que procuraram a literatura da época sobre o assunto estatísticas vitais. E foram bons neste metiér. Não por acaso, o Instituto Brasileiro de Geografia e Estatística - IBGE, por intermédio de seu Conselho Nacional de Estatística, concedeu a José Luiz Sayão de Bulhões Carvalho, em 1939, o título de "Fundador da estatística nacional". E seu mentor, Aureliano Portugal, também foi merecedor de mesma honraria. O Rio de Janeiro, enquanto corte ou mesmo como Capital Federal da República teve o privilégio de contar com brilhantes cientistas, todos médicos, que militaram entre números auscultando a saúde das estatísticas pátrias, auxiliando governos, fundamentando teses e hipóteses, traçando com régua e compasso os caminhos do progresso material da Nação. Eles souberam fazer das ciências estatísticas instrumento indispensável ao político e ao administrador.

O tema demógrafos sanitaristas andou esquecido nos últimos anos. Quando estávamos elaborando a Dissertação de Mestrado Pátria de questionário: o clamor dos tipos quando o Brasil fez 100 anos (Santos, 2004), nos deparamos com esses homens de ciência do passado e procuramos estudá-los. Surpreendentemente, as fontes eram pouquíssimas, os demógrafos, incluindo os especialistas em Demografia Histórica, sequer tinham conhecimento sobre eles. Por nossa iniciativa, resolvemos tirar o assunto das sombras da História, estudar o tema, não só para a Dissertação, mas para desenvolvê-lo no Projeto História das Estatísticas, no Centro de Documentação e Disseminação de Informações do IBGE. A partir da Dissertação e de palestras que ministramos sobre o tema, outros articulistas desenvolveram o assunto em outros estudos, inclusive já publicados. 


\section{Referências bibliográficas}

A Noite, 29/9/1919, p.2. . 4/10/1919, p. 2. 9/10/1919, p. 2. .15/10/1919, p. 2.

BACKEUSER, E. Habitações populares. Relatório apresentado ao Exmo. Sr. Dr. J. J. Seabra, ministro da Justiça e Negócios Interiores. Rio de Janeiro: Imprensa Nacional, 1906. p. 105.

BRASIL. Coleção das leis do Império do Brasil de 1850. Rio de Janeiro: Tipografia Nacional, Tomo XI, parte I, 1851. p. 299

. Diretoria Geral de Saúde Pública. Relatório sobre a salubridade da cidade do Rio de Janeiro em geral e a febre amarela em particular para subir à Augusta Presença de S. M. o Imperador, por seu reverente e respeitoso médico, Dr. Francisco de Paula Candido, presidente da Junta de Higiene Pública. Rio de Janeiro: Tipografia Nacional, 1853.

. Ministério dos Negócios do Império. Relatório apresentado à Assembleia Geral Legislativa na primeira sessão da décima oitava legislatura pelo ministro e secretário de Estado interino dos Negócios do Império, conselheiro de Estado Manoel Pinto de Souza Dantas. Rio de Janeiro: Tipografia Nacional, Anexo 1, 1882. p. 1.

- Ministério dos Negócios do Império. Relatório apresentado à Assembleia Geral Legislativa na terceira sessão da décima sétima legislatura pelo ministro e secretário de Estado interino dos Negócios do Império, conselheiro Barão Homem de Mello. Rio de Janeiro: Tipografia Nacional, 1880.

- Ministério dos Negócios do Império. Relatório apresentado à Assembleia Geral Legislativa na primeira Sessão da décima nona Legislatura pelo ministro e secretário de Estado dos Negócios do Império João Florentino Meira de Vasconcellos. Rio de Janeiro: Imprensa Nacional, 1885. p. 2.

. Ministério dos Negócios do Império. Relatório apresentado à Assembleia Geral Legislativa na primeira Sessão da vigésima Legislatura pelo ministro e secretário de estado dos Negócios do Império Barão de Mamoré. Rio de Janeiro: Imprensa Nacional, 1886. p.86.

- Ministério dos Negócios do Império. Relatório apresentado à Assembleia Geral Legislativa na segunda Sessão da vigésima Legislatura pelo ministro e secretário de estado dos Negócios do Império Barão de Mamoré. Rio de Janeiro: Imprensa Nacional, 1887. p. 102.

. Ministério dos Negócios do Império. Relatório apresentado à Assembleia Geral legislativa na quarta Sessão da vigésima Legislatura pelo Ministro e Secretário de Estado dos Negócios do Império Antonio Ferreira Vianna. Rio de Janeiro: Imprensa Nacional, 1889. p.144.

. Recenseamento do Brasil realizado em 1 de setembro de 1920. População do Rio de Janeiro, vol. II, $1^{\text {a }}$ parte. Rio de Janeiro: Tipografia da Estatística, 1923.

. Anuário Estatístico do Brasil. Instituto Nacional de Estatística, 1936. 
CARVALHO, Lia de Aquino. Contribuição ao estudo das habitações populares: Rio de Janeiro: 1866-1906. Rio de Janeiro: Secretaria Municipal de Cultura, Dep. Geral de Doc. E Inf. Cultural, Divisão de Editoração, 1995. p.144.

CRUZ, Oswaldo Gonçalves. Relatório apresentado a Sua Excia. o Sr. Ministro de Estado da Justiça e Negócios Interiores pelo Diretor Geral de Saúde Pública - 1903. Rio de Janeiro: s.n., 1904. p. 7.

DAVID, Helena Maria Scherlowski Leal. Notas sobre a relação entre o estado e a sociedade brasileira na produção e disseminação de informações em saúde pública. Informare: Cadernos do programa de pós-graduação em Ciência da Informação/CNPq - Instituto Brasileiro de Informação em Ciência e Tecnologia. UFRJ - Escola de comunicação vol. 2, n. 1 (1996) - Rio de Janeiro: CNPq/IBICT-UFRJ/ECO, 1996. p. 99.

GAZETA DE NOTÍCIAS, 23/9/1906, p. 6.

LIMA, Nisia Trindade, HOCHMAN, Gilberto. Condenado pela raça, absolvido pela medicina: o Brasil descoberto pelo movimento sanitarista da Primeira República. In: MAIO, Marcos Chor, SANTOS, Ricardo Ventura (orgs.) Raça, Ciência e Sociedade. Rio de Janeiro: Fiocruz; Centro Cultural Banco do Brasil, 1996. 252p. p. 23-40.

LOBO, Eulalia Maria Lahmeyer. História do Rio de Janeiro (do capital comercial ao capital industrial financeiro). Rio de Janeiro: IBMEC, 1978, v.1. p. 360.

NUNES, Everardo Duarte. Sobre a História da Saúde Pública: idéias e autores. Ciência, saúde coletiva, vol. 5, n. 2, p. 253, 2000.

OLIVEIRA, Lucia Lippi. A questão nacional na primeira república. São Paulo: Brasiliense, 1990.

O Paiz, 3/8/1919, p. 3. .9/10/1919, p. 3. . 11/10/1919, p. 4. .10/10/1919, p. 2.

PEREIRA, Celso das Mercês. Origem e alguns aspectos legais do registro civil. Boletim Demográfico. Rio de Janeiro: vol. 13, n. 2, pp. 5-9, 1982.

ROSEN, George. Uma história da Saúde Pública. São Paulo: Hucitec: Editora da Universidade Estadual Paulista; Rio de Janeiro: Associação Brasileira de Pós-Graduação em Saúde Coletiva, 1994. p. 113.

SANTOS, Marco A. M. Pátria de questionário: o clamor dos tipos quando o Brasil fez 100 anos. Dissertação de Mestrado em Estudos Populacionais e Pesquisas Sociais, defendida em 18 de junho de 2004, na Escola Nacional de Ciências Estatísticas - ENCE, 2004.

SENRA, Nelson. O saber e o poder das estatísticas. Uma história das relações dos estaticistas com os Estados Nacionais e com as Ciências. Rio de Janeiro: IBGE, 2005.

copyright (c) cccreative Santos 